\title{
Çikolata ile zenginleştirilmiş portakal sularının bazı kalite parametrelerinin incelenmesi
}

\author{
Investigation of some quality parameters of orange juices enriched with chocolate
}

\author{
Filiz UÇAN TÜRKMEN",1,a, Muhammed Mustafa GEZER ${ }^{2, b}$, Merve PAKSOY ${ }^{1, c}$, \\ Fatma Rumeysa ATÇI ${ }^{1, d}$, Rabia ALMAS ${ }^{1, e}$ \\ ${ }^{1}$ Kilis 7 Aralı Üniversitesi, Mühendislik-Mimarlık Fakültesi, Glda Mühendisliği Bölümü,79000, Kilis, Türkiye
}

• Geliş tarihi / Received: 29.04.2021 • • Düzeltilerek geliş tarihi / Received in revised form: 03.10.2021 • Kabul tarihi / Accepted: 26.10 .2021

\begin{abstract}
Öz
$\mathrm{Bu}$ çalışmada pastörize edilmiş portakal sularına farklı oranlarda (\%1, \%2.5 ve \%5) eritilmiş çikolata ilave edilerek çikolatalı portakal suyu üretilmiştir. Bu çalışmanın amacı, iki besin grubunu bir araya getirerek besleyici ve lezzetli bir ürün elde etmektir. Bu iki besin grubunun birleşimi ile fenolik ve antioksidan içeriği yüksek, farklı bir aromaya ve hoş bir tada sahip yeni bir ürün elde edilmesi amaçlanmıştır. $\mathrm{Bu}$ amaçla, $75^{\circ} \mathrm{C} 120$ sn pastörizasyon koşullarında isıl işleme tabi tutulan ve \%2.5 çikolata içeren pastörize portakal suyunda yaklaşık \% 4'lük kalıntı pektin metil esteraz (PME) aktivitesi tespit edilmiştir. En yüksek pH (4.13), suda çözünür kuru madde (SÇKM) $\left(13.20^{\circ} \mathrm{B}\right), \mathrm{HMF}(92.18 \mathrm{mg} / \mathrm{L})$ ve viskozite $(2.50 \mathrm{cP})$ değerleri $\% 5$ oranında eritilmiş çikolata ilave edilen portakal sularında tespit edilmiştir. En yüksek fenolik madde miktarı $(2728.5 \mathrm{mg} / \mathrm{L})$, flavonoid madde miktarı $(35.58 \mathrm{mg} / \mathrm{L})$ ve askorbik asit değerleri de $(84.42 \mathrm{~g} / \mathrm{mL})$ yine $\% 5$ çikolata içeren pastörize portakal suyunda ölçülmüştür. Çikolatalı portakal suyu örnekleri arasında antioksidan aktivitesi en yüksek örnek $\% 84.37$ değeri ile $\% 5$ oranında çikolata içeren portakal suyu olmuştur. L*değeri en yüksek olan ham portakal suyu (11.43) iken; $+a^{*}$ değeri en yüksek $\% 5$ çikolata eklenmiş pastörize portakal suyu (16.63); $+\mathrm{b}^{*}$ değeri en fazla \%1 çikolata içeren pastörize portakal suyu (30.85); Hue değeri en yüksek pastörize portakal suyu (88.99); Kroma değeri en yüksek \%2.5 çikolata içeren pastörize portakal suyu (33.14); en yüksek esmerleşme indeksi değeri \% 2.5 çikolata içeren pastörize portakal suyu (0.636 (abs.)) olarak tespit edilmiştir. Çikolata ilave edilen portakal suları arasındaki duyusal analiz bakımından en çok \%5 çikolata eklenmiş pastörize portakal suyu (3.58) beğenilmiştir.
\end{abstract}

Anahtar kelimeler: Antioksidan aktivite, Çikolata, Duyusal, Fenolik, Portakal, PME

\begin{abstract}
In this study, chocolate orange juice was produced by adding melted chocolate at different rates $(1 \%, 2.5 \%$ and $5 \%)$ to pasteurized orange juice. The aim of this study is to combine two food groups to obtain a nutritious and delicious product. It is aimed to obtain a new product with a high phenolic and antioxidant content, a different aroma and a pleasant taste with the combination of these two food groups. For this purpose, approximately $4 \%$ residual pectin methyl esterase (PME) activity was determined in pasteurized orange juice containing $2.5 \%$ chocolate and subjected to heat treatment at " $75^{\circ} \mathrm{C}$ $120 \mathrm{sec}$ " pasteurization conditions. The highest $\mathrm{pH}$ (4.13), water soluble solids (WSS) (13.20 $\left.{ }^{\circ} \mathrm{B}\right), \mathrm{HMF}(92.18 \mathrm{mg} / \mathrm{L})$ and viscosity $(2.50 \mathrm{cP})$ values were determined in orange juices with $5 \%$ melted chocolate added. The highest phenolic content $(2728.5 \mathrm{mg} / \mathrm{L})$, flavonoid content $(35.58 \mathrm{mg} / \mathrm{L})$ and ascorbic acid values $(84.42 \mathrm{~g} / \mathrm{mL})$ were also found in pasteurized orange juice containing 5\% chocolate. Among the chocolate orange juice samples, the sample with the highest antioxidant activity was the orange juice containing $5 \%$ chocolate with a value of $84.37 \% . L *$ value is the brightest in untreated orange juice (11.43); $+a *$ value is the highest in pasteurized orange juice (16.63) containing $5 \%$ chocolate; $+b *$ value is the highest in the pasteurized orange juice (30.85) containing up to 1\% chocolate (30.85); Hue value is the highest in pasteurized orange juice (88.99); pasteurized orange juice containing $2.5 \%$ chocolate has the highest chromium content (33.14); The highest browning index value was found in the pasteurized orange juice (0.636 (abs.)) containing $2.5 \%$ chocolate. Pasteurized orange juice (3.58) containing 5\% chocolate is the most preferred among the samples of chocolate containing orange juices.
\end{abstract}

Keywords: Antioxidant activity, Chocolate, Sensory, Phenolic, Orange, PME

\footnotetext{
${ }^{{ }^{*} a}$ Filiz UÇAN TÜRKMEN; ucanfiliz@gmail.com, Tel: (0(348) 81426 66/1812, orcid.org/0000-0002-3653-9433

${ }^{\mathrm{b}}$ orcid.org/0000-0003-2588-8774 $\quad{ }^{\mathrm{c}}$ orcid.org/), 0000-0001-9949-8985 $\quad$ orcid.org/0000-0003-3870-9579

'orcid.org/0000-0002-8236-9869
} 


\section{Giriş \\ 1. Introduction}

Turunçgiller 1lıman iklime sahip olan birçok ülkede yetiştiriciliği yapılan ve anavatanlarının Hindistan, Çin ve Güneydoğu Asya olduğu bilinen meyve ağaçları türleridir. Turunçgiller portakal, limon, mandarin ve altıntop gibi yetiştiriciliği yaygın ve ekonomik değere sahip türleri içermekte iken bunların yanı sıra az bilinen bergamot, ağaç kavunu ve şadok türlerini de içermektedirler. Askorbik asit değerleri yüksek olup insan sağlığı açısından önemli yararları olan turunçgiller, meyveleri gıda olarak sofralık taze tüketimi ya da meyve suyu, reçel ve marmelat olarak değerlendirilen ayrıca kozmetik ve tıp sektörlerinde de hammadde olarak kullanılan bitki türleridir (Akgün, 2006). Citrus sinensis (L.) Osbeck olarak bilinen portakal, turunçgiller içindeki önemli türlerden birisidir (Cemeroğlu, 2004; Hasdemir, 2007).

Turunçgillerin fenolik bileşikler, karotenoidler ve C vitamini gibi birçok sağlığa yararlı bileşikleri bulundurdukları ve bunların yanı sıra yüksek oranda besin öğesi içerdikleri bilinir. $\mathrm{Bu}$ söz konusu bileşikler antioksidan kapasiteye sahip oldukları için vücutta serbest radikallerin yol açtığı oksidatif zarara karşı hücreleri korurlar. C vitamininin ise beslenme için temel bir bileşen olduğu ve antioksidan kapasitesinin yüksekliği nedeniyle birçok gıda ürününde katkı maddesi olarak kullanıldığ 2006; Dhuique-Mayer vd., 2007; Polydera vd., 2004; Xu vd., 2007).

Çikolata; kakao yağı, şeker ve çikolata tipine göre kakao kütlesi ve/veya toz kakao, süt ve/veya süt tozu ve çeşni maddeleri, ayrıca gıda katkı maddeleri yönetmeliğinde izin verilen katk1 maddelerinin de ilavesi ile tekniğine uygun şekilde hazırlanıp kalıplanarak elde edilen bir mamuldür (Anonim, 1990). Çikolatanın tarihteki ilk izlerinin İ.Ö. 1500'lü yıllara dayanmaktadır. Olmekler (Meksika Körfezi'nde bulunan Yucatan Yarımadası'nda yaşayan halk) kakao tohumlarını öğütmüş ve daha sonra baharat, mısır unu ve su ekleyerek karıştırmış ve sonuçta bu ürünü "kakawa" olarak adlandırdıkları bir enerji içeceği olarak tasarlamışlardır. Çikolatanın daha sonraki izleri Aztekler döneminde başlamış; Aztekler, kakaoya ilahi bir anlam yüklemiş; kendilerine tanrılar tarafindan verilmiş bir hediye olduğuna inanmış ve kakao ağacına "Tanrıların Yemeği" denilen "Theobramba Cacao" ismini vermişlerdir. Aztekler'in "chocolatl" dedikleri içecek ise çikolatayı seçkin tabakanın popüler içeceğine dönüştürmüştür (Coe \& Coe, 1996). Çikolatanın potansiyel olarak uyarıcı, gevşetici ve antidepresan özellikleriyle birlikte neşe ve zevk ile alakasının olduğu bilinmektedir. Gevşetici ve ağrı kesici etkisini beyinde endorfin salgisin arttırmasıyla gerçekleştirir. Kanser ve kalp hastalıkları risklerini azalttığ 1 , tabii bir enerji kaynağı olmasıyla birlikte acı hissi ile gerginliği aza indirmede faydalıdır (Anonim, 2010; Thamke, 2009). Aynı zamanda çikolotanın içeriğinde bulunan polifenollerin damar deformasyonunu önlediği, astıma neden olan lipoksigenaz üretimini bloke ettiği ve bağışıklık sistemini güçlendirdiği yönünde literatürde bilgiler mevcuttur (Kargın \& Güneş, 2017).

Portakalın C vitamini açısından güçlü bir antioksidan olmasının yanı sıra çikolatanın da antioksidan özelliği ve kalp-damar rahatsılıkları üzerine olumlu faydaları bulunduğu yıllardan beri bilinmektedir. Bu çalışmanın amacı, iki besin grubunu (çikolata ve portakal suyu) bir araya getirerek besleyici ve lezzetli bir ürün elde etmektir. Bu iki besin grubunun birleşimi ile fenolik ve antioksidan içeriği yüksek, farklı bir aromaya ve hoş bir tada sahip yeni bir ürün elde edilmesi amaçlanmıştır.

\section{Materyal ve metot}

\section{Material and method}

\subsection{Materyal}

2.1. Material

$\mathrm{Bu}$ çalışmada, Kilis'te bulunan semt pazarından temin edilen Citrus sinensis bitkisine ait portakal meyvesi kullanılmıştır. Temin işlemini takiben meyveler Kilis 7 Aralık Üniversitesi Gıda Mühendisliği Bölümü Gıda İşleme Laboratuvarında $+4^{\circ} \mathrm{C}$ 'de muhafaza edilmiş ve hemen portakal suyu üretimine geçilmiştir.

\subsection{Metot}

\subsection{Method}

Portakal suyu üretimi Şekil 1'de verilen akış diyagramına uyularak yapılmıştır. Şekil 1'den anlaşılacağ1 üzere öncelikle portakallar yıkama işlemine tabi tutulmuş; orta eksene dik şekilde ikiye bölünen portakallar el tipi paslanmaz çelik portakal sıkacağı aracıllı̆̆yla sıkılmıştır. Elde edilen portakal suları $1 \mathrm{~mm}$ paslanmaz çelik eleklerden geçirilerek pulp ayırma işlemi yapılmıştır. Portakal suyuna $\% 1,2,5$ ve 5 düzeyinde sütlü çikolata (Buono, BİM, Türkiye) eklenmiştir. Elde edilen örneklerin kısaltmalarında; HPS: ham portakal suyunu, PPS: pastörize portakal suyunu ve ÇPS ise çikolatalı 
portakal suyunu ifade etmektedir. Çikolata portakal suyuna eklenmeden önce benmari usulü ile eritilmiş ve direkt olarak meyve suyuna eklenmiştir. 200 ml'lik kahverengi cam şişelere 175 'er ml dolumu yapılan portakal suları; taçkapak kapama aletiyle (yarı otomatik el tipi) kapatılmıştır. Pektin metil esteraz (PME) enziminin inaktivasyonuna dayanan denemelerle belirlenen sicaklık ve süre parametrelerine göre pastörizasyon işlemi uygulanmış ve pastörizasyon normu olarak $75^{\circ} \mathrm{C} 120$ sn uygun bulunmuştur. Laboratuvar tipi çalkalamalı su banyosunda (Memmert Marka Wisd, Wisebath Model) pastörizasyon işlemi uygulanmış ve çalışma 3 tekerrürlü olarak gerçekleştirilmiştir.

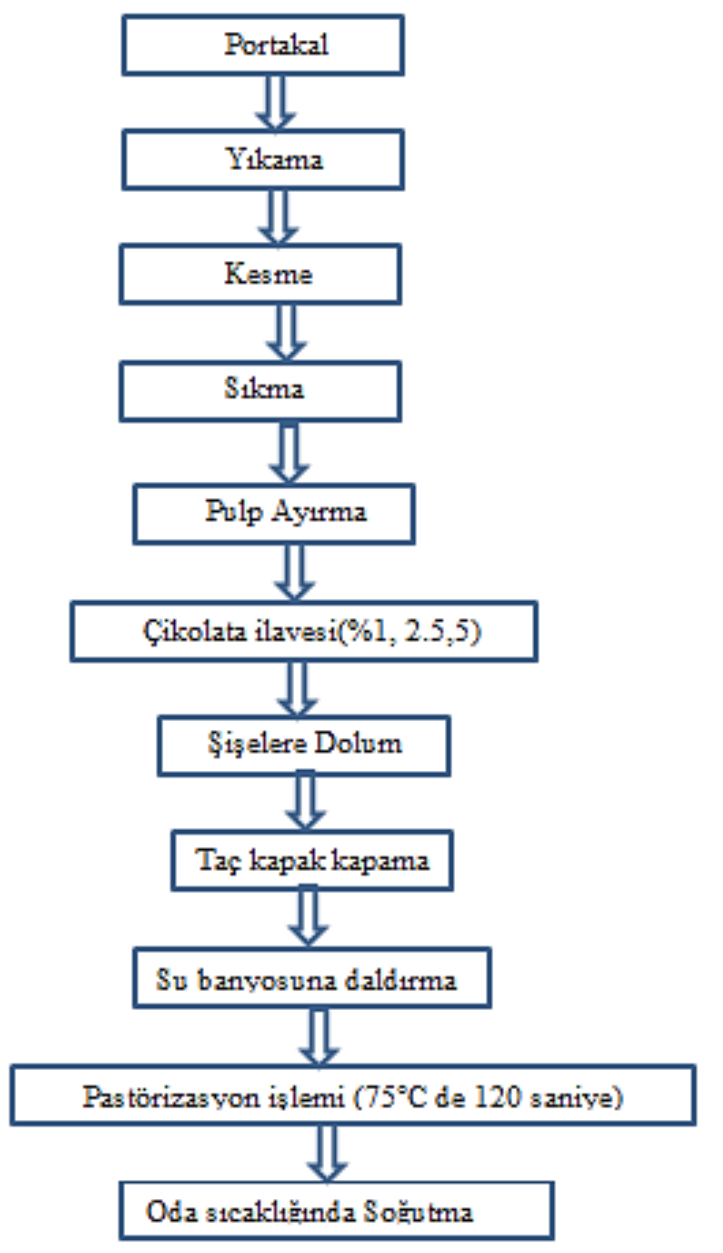

Şekil 1. Pastörize çikolatalı portakal suyu üretim akış şeması

Figure 1. Production flow chart of pasteurized chocolate orange juice

Pastörize portakal suları oda sıcaklığına kadar musluk suyu ile soğutulmuş; aşağıdaki analizler uygulanmıştır:

\subsection{Analizler \\ 2.3. Analysis}

\subsubsection{Meyve suyu veriminin belirlenmesi}

2.3.1. Determination of juice yield

Kullanılan meyve suyu ağırlı̆̆ının meyve ağırlığına bölünmesi ile gerekli hesaplama yapılmıştır (Cemeroğlu, 1992).

\subsection{2. pH tayini}

2.3.2. $\mathrm{pH}$ determination

pH analizinde cam elektrotlu WTW marka pHmetre (Weilheim, Germany) kullanılmış ve ölçümler oda sıcaklığında gerçekleştirilmiştir (Cemeroğlu, 1992).

\subsubsection{Titrasyon asitliği (TA) tayini \\ 2.3.3. Titration acidity (TA) determination}

$5 \mathrm{ml}$ portakal suyu alınarak $0.1 \mathrm{~N} \mathrm{NaOH}$ çözeltisi ile $\mathrm{pH}$ 8.1' e kadar titre edilmiş ve sonuçlar g/100 $\mathrm{mL}$ olarak hesaplanmıştır (Sànchez-Moreno vd., 2003).

\subsubsection{Suda çözünür kuru madde miktarı (SÇKM)}

2.3.4. Amount of water-soluble dry matter (SSCM)

SÇKM miktarı masa tipi Abbe refraktometresi (J.P. SELECTA, S.A) ile $20^{\circ} \mathrm{C}$ ' de ölçülmüş ve sonuçlar Briks olarak ifade edilmiştir (Sànchez-Moreno vd., 2003).

\subsubsection{Pektin metil esteraz (PME) kalıntı aktivite tayini}

2.3.5. Pectin methyl esterase (PME) residual activity determination

$10 \mathrm{~mL}$ portakal suyu örneği bir behere aktarılarak üzerine $30^{\circ} \mathrm{C}^{\prime}$ ye getirilmiş pektin çözeltisinden $(0.1 \mathrm{M} \mathrm{NaCl}$ ve $\% 1$ pektin içeren) $20 \mathrm{~mL}$ eklenmiştir. Hemen ardından $\mathrm{pH}$ metre elektrotu daldırılmış ve 2N'lik NaOH çözeltisiyle pH'7'ye ulaşılmış; $0.05 \mathrm{~N} \mathrm{NaOH}$ kullanılarak pH 7.7' ye ayarlanmış; pH 7.7 olduğunda $0.1 \mathrm{~mL} 0.05 \mathrm{~N}$ $\mathrm{NaOH}$ ilave edilmiş; kronometre çalıştırılarak pH tekrar 7.7' ye geldiğinde kronometre durdurulmuş ve geçen zaman kayıt altına alınmıştır. Aşağıda yer alan formül (1) yardımıyla PME aktivitesi hesaplanmıştır (Kimball, 1991).

$\%$ Kalıntı PME Aktivitesi $=\mathrm{A}_{\mathrm{t}} / \mathrm{A}_{0} \times 100$

$\mathrm{A}_{\mathrm{t}}$ : İşlem Sonrası PME Aktivitesi

$\mathrm{A}_{0}$ :Başlangıç PME Aktivitesi 


\subsubsection{Su aktivitesi}

\subsubsection{Water activity}

Su aktivitesi ölçümü için kalibrasyonu daha önceden yapılmış ölçüm cihazı (NovasinaLabtouch-aW) kullanılmıştır.

\subsubsection{Renk analizi}

\subsubsection{Color analysis}

Renk (CIE L*, $a^{*}, b^{*}$ ) analizi, el tipi renk cihazı (HunterLabminiscan EZ, ABD) ile belirlenmiştir. $50 \mathrm{~mL}$ örnek küvete alınarak analiz edilmiştir. Sonuçlar CIELAB rengine göre verilmiştir. $\mathrm{Bu}$ sistemde, $L^{*}$ açıklık/koyuluk (0: siyah, 100: beyaz), a* kırmızı / yeşil değerini ((+): kırmızı, (-): yeşil) ve $b^{*}$ sarı / mavi değerini ((+): sarı; (-): mavi) vermektedir. Buna ek olarak, Hue ve kroma değerleri aşağıdaki formüller $(2,3)$ baz alınarak kullanılmıştır.

Hue $*=\arctan \left(\mathrm{b}^{*} / \mathrm{a}^{*}\right)$

$\mathrm{C}^{*}=\sqrt{(a *) 2+(b *) 2}$

\subsubsection{HMF analizi}

\subsubsection{HMF analysis}

5-hidroksimetilfurfural (HMF) içeriği, kırmızı renkli bir kompleks oluşturan, barbitürik asit, ptoluidin ve HMF arasındaki kolorimetrik reaksiyona dayalı olarak Cemeroğlu (2007) tarafindan geliştirilmiş prosedür izlenerek HMF miktarı tespit edilmiştir.

\subsubsection{Toplam fenolik madde miktarı tayini}

2.3.9. Determination of total phenolic substance content

Örneklerin toplam fenolik içeriği spektrofotometrik yöntem kullanılarak ölçülmüştür (Uçan Türkmen vd., 2018). Örneklerin $0.5 \mathrm{~mL}^{\prime} \mathrm{si}$ $2.5 \mathrm{~mL} \% 10$ Folin-Ciocalteu reaktifi ve $2.5 \mathrm{~mL}$ \%7.5 $\mathrm{NaHCO}_{3}$ ile karıștırılmıştır. Reaksiyon karışımları $45^{\circ} \mathrm{C}$ deki su banyosu içerisinde 45 dakika inkübe edilmiştir. Daha sonra örneklerin absorbans1, $765 \mathrm{~nm}$ 'de spektrofotometre cihazında (Biochrom, Libra S60, B, İngiltere) ölçülmüştür. Farklı konsantrasyonlarda gallik asit çözeltisi kullanılarak standart bir eğri hazırlanmıştır. Örneklerdeki fenolik içeriği ölçülen absorbansa göre gallik asit eşdeğeri (GAE) (mg/L) olarak ifade edilmiştir.

\subsubsection{Toplam flavonoid madde miktarı tayini}

2.3.10. Determination of total flavonoid substance content

Örneklerin toplam flavonoid içeriği, alüminyum klorür kolorimetrik yöntemi (standart olarak kateşol) ile belirlenmiştir. Örneklerin $1 \mathrm{ml}$ si seyreltilerek (1:10), $0.3 \quad \mathrm{ml} \quad \% 5 \quad \mathrm{NaNO}_{2}$ ile karıştırılmıştır. Elde edilen karışım bir vorteks ile karıștırıldıktan sonra 5 dakika boyunca inkübe edilmiştir. Daha sonra $0.6 \mathrm{~mL} \% 10 \mathrm{AlCl}_{3} \cdot 6 \mathrm{H}_{2} \mathrm{O}$ solüsyonu ilave edilmiş ve inkübe edildikten sonra (5 dakika) elde edilen reaksiyon karışımı $2 \mathrm{~mL} 1 \mathrm{M}$ $\mathrm{NaOH}$ solüsyonu ilave edilerek damıtılmış su ile 10 mL'ye getirilmiştir. Karışımın absorbansı UVVIS spektrofotometre (Biochrom, Libra S60, B, İngiltere) ile $510 \mathrm{~nm}$ 'de ölçülmüştür. Toplam flavonoid içeriği bir kalibrasyon eğrisinden hesaplanarak sonuçlar kateşol eşdeğeri $(\mathrm{mg} / \mathrm{L})$ olarak ifade edilmiştir (Uçan Türkmen vd., 2018).

\subsubsection{Toplam karotenoid madde miktarı tayini 2.3.11. Determination of the total amount of carotenoid substance}

Portakal sularının toplam karotenoid miktarları için Lee vd., (2001)'nın daha önce belirtmiş oldukları yöntem laboratuvarımız koşullarına uygun hale getirilerek kullanılmıştır. Bunun için $5 \mathrm{~mL}$ portakal suyu teflon bir tüpe aktarılarak üzerine $10 \mathrm{ml}$ ekstraksiyon çözeltisi (hekzan: aseton: metanol/50:25:25, \% 0.1 BHT içeren) ilave edilmiştir. $\mathrm{Bu}$ işlemi takiben bir karıştırma işlemi uygulandıktan hemen sonra santrifüjleme işlemine (4000 rpm, $10 \mathrm{dk}, 4^{\circ} \mathrm{C}$ ) geçilmiştir. Santrifüjleme sonrası vakit kaybetmeden $450 \mathrm{~nm}$ 'de absorbans ölçümü alınmış ve toplam karotenoid madde miktarı $\beta$-karoten cinsinden aşağıdaki formüle göre (4) ifade edilmiştir.

Toplam karetonoid $(\mathrm{mg} / 100 \mathrm{~mL})=$ Absorbans $\times$ $\mathrm{SF} / \mathrm{E}^{1 / 2} \times 1000$

SF: Seyreltme faktörü

$\mathrm{E}^{1 / 2}=$ Ekstinksiyon katsayıs1 (2505)

\subsubsection{Askorbik asit tayini}

2.3.12. Determination of ascorbic acid

Örneklerdeki askorbik asit miktarları spektrofotometre (Biochrom, Libra S60, B, İngiltere) ile test edilmiştir. Renk reaktifi olarak 2,6-diklorofenol-indofenol kullanılmış ve absorbans ölçümleri 518 nm'de yapılmıştır. Örneklerdeki askorbik asit içeriği, L askorbik asit ile hazırlanan standart bir eğri ile karşılaştırılarak hesaplanmıştır (Uçan Türkmen vd., 2018). 


\subsubsection{Antioksidan aktivite tayini}

\subsubsection{Determination of antioxidant activity}

Numunelerin antioksidan kapasitesi, kararlı DPPH (2,2-difenil 1-pikrilhidrazil) bileşiği ile tespit edilmiştir. Bu deney, pembe kararlı bir bileşik olan DPPH radikalinin yıkımı sonucu, renkteki azalmanın spektrofotometrik (Biochrom, Libra $\mathrm{S} 60, \mathrm{~B}$, İngiltere) olarak ölçülmesine dayanmaktadır. $100 \mu \mathrm{L}$ numune alınıp, üzerine 3.9 $\mu \mathrm{L}$ DPPH (metanolde $0.025 \mathrm{~g} / \mathrm{L}$ ) çözeltisi eklenir. Karışımlar karanlıkta, oda sıcaklığında 120 dakika inkübe edilmiştir. Daha sonra kalan DPPH miktarı, 515 nm'de ölçülerek belirlenmiştir. Test numunelerinde, DPPH'nin inhibisyonu “\% İnhibisyon $=\left(A_{\text {kontrol }} A_{\text {örnek }}\right) \quad / \quad A_{\text {kontrol }} * 100$, formülüne göre hesaplanmıştır (Uçan Türkmen vd., 2018).

\subsubsection{Viskozite analizi}

\subsubsection{Determination of viscosity}

Portakal sularının viskozite değeri Fungilab Expert viscometer (Model 1, Sant feliu de Llobregat. Barcelona) kullanılarak 100 rpm'de L4 spindle ile belirlenip cP olarak ifade edilmiştir.

\subsubsection{Esmerleşme indeksi}

\subsubsection{Browning index}

$5 \mathrm{~mL}$ örnek alınarak üzerine $5 \mathrm{~mL}$ etil alkol (\%95) eklenerek karıştırılmış ve sonra santrifüjlenmiştir (4000 rpm, 10 dakika, $40^{\circ} \mathrm{C}$ ). Süpernatant $0.45 \mu \mathrm{m}$ steril filtreden geçirilerek spektrofotometrede (Biochrom, Terazi S60, B, İngiltere) 420 nm'de etil

Tablo 1. Portakal meyvesinin genel özellikleri Table 1. General characteristics of orange fruit alkole karşı okunmuş ve değerler (ABS) olarak ifade edilmiştir (Meydav vd., 1977).

\subsubsection{Duyusal analiz}

2.3.16. Sensory Analysis

Grafik skalası metodu aracıllı̆̆ıla 13 kişilik panelist grubu baz alınarak genel izlenim, tat ve lezzet, koku, renk, bulanıklık özelliklerinin yer aldığ 1 duyusal form kullanılarak duyusal analiz değerlendirmesi gerçekleştirilmiştir (Altuğ, 1993; Watts vd., 1989).

\subsubsection{7. İstatistiksel analiz \\ 2.3.17. Statistical analysis}

Elde edilen veriler tesadüf parselleri deneme desenine göre SPSS (23.0) istatistik paket program1 kullanılarak test edilmiştir. Varyans analizi sonucunda özelliklerin ortalaması Duncan çoklu karşılaştırma testine göre test edilmiştir (Bek \& Efe, 1988).

\section{Bulgular ve tartışma \\ 3. Findings and discussion}

\subsection{Portakalın meyve özellikleri \\ 3.1. Fruit characteristics of orange}

Tablo 1'de çalışmamızda kullandığımız portakal meyvesinin genel özellikleri bulunmaktadır. 10 adet portakal seçilerek portakalların $\mathrm{kg}$ ağırlığı $2.09 \mathrm{~kg}$, kabuk ağırlı $\breve{g}_{1} 1.407 \mathrm{~kg}$, elde edilen meyve suyu miktarı $(\mathrm{kg})$ cinsinden $0.694 \mathrm{~kg}$, meyve suyu miktarı litre cinsinden $670 \mathrm{~mL}$ ortalama meyve suyu verimi ise $\% 33$ düzeyinde belirlenmiştir.

\begin{tabular}{cc}
\hline Özellikler & Değerler \\
\hline Kg ă̆ırlığ & $2.09 \mathrm{~kg}$ \\
Kabuk ağırlı̆̆ $(\mathrm{kg})$ & $1.407 \mathrm{~kg}$ \\
Meyve suyu miktarı $(\mathrm{kg})$ & $0.694 \mathrm{~kg}$ \\
Meyve suyu miktarı $(\ell)$ & $670 \mathrm{~mL}$ \\
Meyve suyu verimi $(\%)$ & $\% 33$ \\
\hline
\end{tabular}

3.2. Pastörizasyon sıcaklı̆ğ ve süresinin seçiminde kalıntı pektin metil esteraz (PME) aktivitesi

3.2. Residual pectin methyl esterase (PME) activity in selection of pasteurization temperature and time

Farklı uygulama sicaklıkları ve süreleri kullanılarak elde edilen pastörize portakal sularında PME aktivitesinin \% 4'e düşürülmesi amaçlanmıştır (Tablo 2). $\mathrm{Bu}$ amaçla, $75{ }^{\circ} \mathrm{C}$ sicaklikta 90 ile 120 saniye, $80^{\circ} \mathrm{C}$ sicaklıkta 40 ile 50 saniye, $85^{\circ} \mathrm{C}$ sicaklıkta 15 ile 55 saniye ve 90 ${ }^{\circ} \mathrm{C}$ 'de $10,15,60,120$ ve 300 saniye pastörizasyon işlemleri uygulanarak ön denemeler gerçekleştirilmiş; elde edilen kalıntı PME aktivitesi değerleri baz alınarak $75^{\circ} \mathrm{C} 120$ sn pastörizasyon normu için yaklaşık \% 4'lük kalıntı PME aktivitesi belirlenmiştir. Ürün kalitesinde kaçınılmaz 
kayıplara yol açacağı için PME aktivitesi daha fazla düşürülmemiş ve \% 4'lük kalıntı aktivitesi uygun bulunmuştur. Polydera vd., (2005) PME'nin $\%$ 95'inin pastörizasyon koşullarında aktivitesini kaybettiğini; kalan \% 5 aktivitenin de uzun süre depolamayı takiben bulanıklık kaybına yol açan ısı direnci daha yüksek olan izoenzimden meydana gelebileceğini vurgulamışlardır.

Tablo 2. Pastörizasyon işleminin portakal sularının kalıntı PME aktivitesi üzerine etkisi

Table 2. Effect of pasteurization on residual PME activity of orange juices

\begin{tabular}{lll}
\hline Sicaklık $\left({ }^{\circ} \mathbf{C}\right)$ & Uygulanan Süre(s) & Kalıntı PME Aktivitesi (\%) \\
\hline 75 & 90 saniye & $5.5 \pm 0.71$ \\
75 & 120 saniye & $5.00 \pm 0.00$ \\
80 & 40 saniye & $5.5 \pm 0.71$ \\
80 & 50 saniye & $4.5 \pm 0.71$ \\
85 & 55 saniye & $5.5 \pm 0.71$ \\
85 & 15 saniye & $4.5 \pm 0.71$ \\
90 & 10 saniye & $4.00 \pm 0.00$ \\
90 & 15 saniye & $4.5 \pm 0.71$ \\
90 & 60 saniye & $4.5 \pm 0.71$ \\
90 & 120 saniye & $5.00 \pm 0.00$ \\
90 & 300 saniye & $6.00 \pm 0.00$ \\
\hline
\end{tabular}

Turunçgillerde PME aktivitesi çok yüksek olup bu enzim metoksil gruplarını ayırarak, pektinin esterleşme derecesini düşürmekte ve ortamdaki $\mathrm{Ca}^{+2}$ iyonuyla birleşip stabilitesini yitirmektedir. Zamanla turunçgil sularında serumun ayrılmasıyla tortu oluştuğu, konsantrede ise jelleşme görüldüğü bilinmektedir. Söz konusu üretimlerde, PME'nin inaktivasyonu gerçekleştirilerek bu enzimin yol açabileceği istenmeyen olaylar sınırlandırılmalıdır. Meyve suyu üretimlerinde son üründe daima PME kalıntısı bulunmakta (\% 4'lük kalıntı aktivite) ve kalıntı PME aktivitenin tespiti ise özellikle ürünün stabilitesiyle ilgili elzem veriler tespit etmektedir (Cemeroğlu, 2007).

Şekil 2'de görüldüğü gibi en fazla $\% 1$ ve $\% 5$ çikolata içeren pastörize portakal sularında kalıntı PME aktivitesi 5 sn olarak tespit edilmiştir.

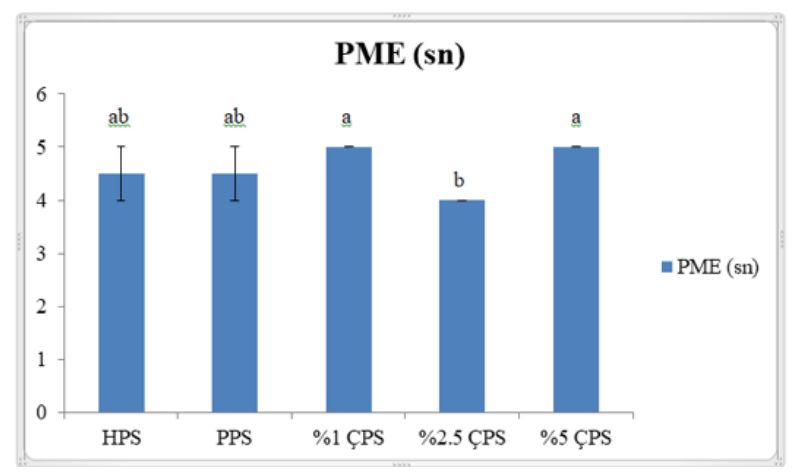

Şekil 2. Portakal suyu örneklerinin kalıntı PME aktivitesi

Figure 2. Residual PME activity of orange juice samples
En az kalıntı PME aktivitesi ise \%2.5 çikolata içeren pastörize portakal suyunda kalıntı PME aktivitenin 4 sn olduğu sonucuna varılmıştır ( $>>0.05)$.

\subsection{Portakal suyu örneklerinin fizikokimyasal özellikleri}

3.3. Physicochemical properties of orange juice samples

Portakal suyu örneklerinin fizikokimyasal özelliklerine ait değerler Şekil 3'de verilmiştir. En yüksek pH değeri $\% 5$ 'lik ÇPS'de 4.13 , en düşük $\mathrm{pH}$ değeri ise \%1'lik ÇPS'de 3.90 olarak belirlenmiştir. Ham portakal suyuna isıl işlem uygulandıkça $\mathrm{pH}$ değerinde (3.96) artış gözlenmiştir. En yüksek pH değeri en yüksek konsantrasyonda çikolata içeren örnekte (\%5'lik ÇPS'de) bulunmuştur. Çikolatanın $\mathrm{pH}$ değeri genellikle 7'den büyük olduğu için ürün bazik bir karaktere sahiptir ve bu bazik maddenin portakal suyuna ilavesi ile $\mathrm{pH}$ değerinde artışlar muhtemeldir. $\mathrm{Bu}$ durum ise eklenen çikolata miktarının artması ile portakal suyunda $\mathrm{pH}$ artışlarının olabileceğinin bir işareti olarak değerlendirilebilir $(\mathrm{p}>0.05)$.

Li-Ying vd., (2008) portakal suyunun fizikokimyasal özellikleri üzerine yaptıkları çalışmada, 7 portakal çeşidinin $\mathrm{pH}$ değerlerinin 3.81 ile 4.31 aralığında olduğunu bildirmişlerdir.

Tablo 3'de görüldüğü gibi ham portakal suyunda SÇKM değeri $12.40^{\circ} \mathrm{B}$; pastörize portakal suyunda ise $12.55^{\circ} \mathrm{B}$ olarak bulunmuştur. En yüksek SÇKM değeri $\% 5$ çikolata içeren pastörize portakal 
suyunda $13.20^{\circ} \mathrm{B}$ olarak tespit edilmiştir. Ham ve pastörize portakal sularını kıyasladığımızda pastörizasyon uygulanınca briks değerinin arttığ gözlemlenmiştir. Çikolata içeren portakal sularında ise çikolata miktarı arttıkça briks değerinin de artış gösterdiği tespit edilmiştir $(\mathrm{p}<0.05)$.

Tablo 3. Portakal suyu örneklerinin fizikokimyasal özellikleri

Table 3. Physicochemical properties of orange juice samples

\begin{tabular}{|c|c|c|c|c|c|c|}
\hline Örnekler & pH & $\begin{array}{l}\text { SÇKM } \\
\text { \% Briks }\end{array}$ & $\begin{array}{l}\text { Titrasyon } \\
\text { asitliği (g/100 } \\
\text { mL) }\end{array}$ & $\begin{array}{l}\text { Su Aktivitesi } \\
\left(\mathbf{a}_{\mathbf{w}}\right)\end{array}$ & $\begin{array}{l}\text { HMF } \\
(\mathrm{mg} / \mathrm{L})\end{array}$ & $\begin{array}{l}\text { Viskozite } \\
\text { (cP) }\end{array}$ \\
\hline HPS & $3.91 \pm 0.00^{\mathrm{d}}$ & $12.40 \pm 0.00^{\mathrm{b}}$ & $0.72 \pm 0.0^{\mathrm{b}}$ & $0.990 \pm 0.0^{\mathrm{a}}$ & $21.22 \pm 0.90^{\mathrm{d}}$ & $2.10 \pm 0.10^{\mathrm{c}}$ \\
\hline PPS & $3.96 \pm 0.00^{\mathrm{b}}$ & $12.55 \pm 0.35^{\mathrm{b}}$ & $0.76 \pm 0.02^{b}$ & $0.990 \pm 0.0^{\mathrm{a}}$ & $21.71 \pm 0.32^{\mathrm{d}}$ & $2.10 \pm 0.10^{\mathrm{c}}$ \\
\hline$\% 1$ ÇPS & $3.90 \pm 0.00^{\mathrm{d}}$ & $11.40 \pm 0.10^{c}$ & $0.83 \pm 0.03^{\mathrm{a}}$ & $0.985 \pm 0.0^{c}$ & $50.63 \pm 0.08^{c}$ & $2.30 \pm 0.00^{\mathrm{b}}$ \\
\hline$\% 2.5$ & $3.94 \pm 0.00^{c}$ & $12.60 \pm 0.20^{\mathrm{b}}$ & $0.83 \pm 0.03^{\mathrm{a}}$ & $0.987 \pm 0.0^{\mathrm{b}}$ & $76.14 \pm 0.81^{\mathrm{b}}$ & $2.30 \pm 0.00^{\mathrm{b}}$ \\
\hline \multicolumn{7}{|l|}{ ÇPS } \\
\hline$\% 5$ ÇPS & $4.13 \pm 0.00^{\mathrm{a}}$ & $13.20 \pm 0.11^{\mathrm{a}}$ & $0.75 \pm 0.05^{\mathrm{b}}$ & $0.988 \pm 0.0^{\mathrm{b}}$ & $92.18 \pm 8.10^{\mathrm{a}}$ & $2.50 \pm 0.00^{\mathrm{a}}$ \\
\hline
\end{tabular}

Valensiya portakalları kullanılarak ekstraksiyonu gerçekleştirilen meyve sularının briksi $12.28^{\circ}$ olarak tespit edilmiştir (Farnworth vd., 2001). Selli vd., (2004) Kozan Yerlisi portakal suyu üzerine yapmış oldukları bir çalışmada SÇKM değerini \% 12.00 olarak belirlemişlerdir. Işık (2008) aynı çeşitte bu değeri \% 11.17-11.83 arasında rapor etmiştir.

Ham portakal suyunda titrasyon asitliği değeri 0.72 $\mathrm{g} / 100 \mathrm{~mL}$; pastörizasyon uygulanan portakal suyunda ise artarak $0.76 \mathrm{~g} / 100 \mathrm{~mL}$ bulunmuştur. En yüksek asitlik derecesi $\% 2.5$ ve $\% 1$ 'lik çikolata içeren pastörize portakal sularında $0.83 \mathrm{~g} / 100 \mathrm{~mL}$ iken en düşük asitlik derecesi hiçbir işlem uygulanmamış olan ham portakal suyunda 0.72 g/100mL olarak belirlenmiştir (Tablo 3). \%5 çikolata içeren portakal suyunda ise asitlik derecesi $0.75 \mathrm{~g} / 100 \mathrm{~mL}$ olarak bulunmuştur $(\mathrm{p}<0.05)$.

Selli vd., (2004) Kozan Yerlisi portakal suyu üzerine yapmış oldukları bir çalışmada titrasyon asitliği değerini $0.93 \mathrm{~g} / \mathrm{mL}$ olarak belirlemişlerdir. Işık (2008) Kozan Yerlisi çeşidinden elde ettiği meyve suyu çalışmasında ise bu değeri $1.64 \pm 0.18$ $\mathrm{g} / 100 \mathrm{~mL}$ olarak rapor etmiştir.

Ham portakal suyunda ve pastörize portakal suyunda en yüksek su aktivitesi $\left(\mathrm{a}_{\mathrm{w}}\right)$ değerleri (0.990) tespit edilmiştir. En düşük su aktivitesi ise $\% 1$ çikolata içeren pastörize portakal suyunda 0.985 olarak belirlenmiştir (Tablo 3). Elde edilen değerler çikolata ilavesinin su aktivitesini düşürdüğünü göstermektedir $(p<0.05)$. Çikolata ilavesi ile ortamdaki serbest su miktarını azaltmakta ve bu durum ise üretilen ürünün daha düşük su aktivitesine sahip olmasına neden olmaktadır.
Furanik aldehitlerin kontrolü, gidalarda esmerleşmenin, tağşş̧̧in, 1sının, uygun olmayan depolamanın ve duyusal özelliklerin değerlendirilmesinde önemlidir. Asitlerle katalizlenen şekerlerin hidrolizinin temel parçalanma ürünü 5- (hidroksimetil)-2furaldehitdir (HMF) (Esteve vd., 2005). HMF'nin oluşumu depolama süresi ve sicaklık ile doğru orantılıdır (Mertoğlu, 2015).

Tablo 3'de görüldüğü gibi en düşük HMF değerleri ham $(21.22 \mathrm{mg} / \mathrm{L})$ ve pastörize portakal sularında $(21.71 \mathrm{mg} / \mathrm{L})$; en yüksek HMF değeri ise $\% 5$ çikolata içeren pastörize portakal suyunda ( 92.18 $\mathrm{mg} / \mathrm{L})$ tespit edilmiştir $(\mathrm{p}<0.05)$. HMF'nin asitli ortamda hegsozun parçalanması ile yada maillard reaksiyonu esnasında bir ara ürün olarak ortaya çıkmaktadır. Maillard reaksiyonları ise sıcaklık, $\mathrm{pH}$ ve su aktivitesi gibi değerlerden etkilenmektedir. HMF değerlerinde meydana gelen artışlar belirtilen durumlar ile açıklanabilir.

Işık (2008), tarafindan yapılan çalışmada Kozan Yerli çeşidinde $\mathrm{HMF}$ değerinin $85^{\circ} \mathrm{C}$ 'de pastörize edilenlerde kontrol grubuna göre önemli derecede fazla olduğu belirlenmiştir. Ağçam (2011), kontrol ve vurgulu elektrik alan tekniği ile işlenen portakal suyu örneklerinde HMF tespit edememiş ancak 1s1 pastörizasyonla işlenen örneklerde ise HMF tespit etmiş olup bu değerlerin 1 sil norm şiddetiyle arttı̆̆ını bildirmiştir.

Viskozite turunçgil suları için önemli bir kalite parametresi olarak kabul edilmektedir. Meyve suyu yoğunluğu ve pulp miktarı viskoziteyi göstermektedir. Bulanıklık kaybı, pektinin metil gruplarını ayıran, kalsiyum pektat çökeltilerinin oluşmasına ve berrak bir görünüme neden olan 
endojen bir enzim olan pektin metil esteraz aktivitesine bağlıdır (Parish, 1998).

En yüksek viskozite değeri $\% 5$ çikolata içeren pastörize portakal suyunda $2.50 \mathrm{cP}$ olarak ölçülmüştür (Tablo 3). En düşük değerlerin ise ham ve pastörize portakal sularında $2.10 \mathrm{cP}$ olduğu tespit edilmiştir $(p<0.05)$. Çikolatada bulunan yağın miktarı ile viskozite arasındaki ilişkiden dolayı bu artış ve azalışların meydana gelmesi olasidir.

\subsection{Portakal suyu örneklerinin biyoaktif bileşikler üzerine etkisi}

3.4. Effect of orange juice samples on bioactive compounds

Portakal suyu örneklerine ait fenolik madde miktarı değerleri Tablo 4'de verilmiştir. Çalışmada, pastörize portakal suyunda fenolik madde miktarının azaldığı gözlenirken, çikolata eklenen pastörize portakal sularında ise fenolik madde miktarlarının arttığı gözlemlenmiştir. Portakal sularında en düşük fenolik madde miktarı pastörize portakal suyunda $897.6 \mathrm{mg} / \mathrm{L}$ olarak bulunmuştur. En yüksek fenolik madde miktarı ise $\% 5$ çikolata içeren pastörize portakal suyunda $2728.5 \mathrm{mg} / \mathrm{L}$ olarak belirlenmiştir. Genel olarak bakıldığında çikolata miktarının fenolik madde miktarını arttırdığı gözlemlenmiştir $(\mathrm{p}<0.05)$.

Yapılan bir çalışmada, portakalda toplam fenolik içerik $112.29 \pm 4.50 \mathrm{mg} \mathrm{GAE} / 100 \mathrm{~g}$ tespit edilmiştir (Chun vd., 2005). Başka bir çalışmada portakal suyunun toplam fenolik içeriğin $684.2 \pm 1.0$ $634.6 \pm 0.9 \mathrm{mg}$ kafeik asit eşdeğeri/l olduğu belirlenmiştir (Klimczak vd., 2007). Bu çalışmada, en yüksek flavonoid miktarı $\% 5$ çikolata eklenmiş pastörize portakal suyunda $(35.58 \mathrm{mg} / \mathrm{L})$ tespit edilmiştir (Tablo 4). En düşük değer ise ham portakal suyunda $(7.67 \mathrm{mg} / \mathrm{L})$ bulunmuştur. Is1 işlem uygulanıp çikolata ilavesi yapıldıkça toplam flavonoid miktarının arttığı gözlemlenmiştir $(\mathrm{p}<0.05)$.

Tablo 4. Portakal suyu örneklerinin biyoaktif bileşikler üzerine etkisi

Table 4. Effect of orange juice samples on bioactive compounds

\begin{tabular}{llllll}
\hline Örnekler & $\begin{array}{l}\text { Toplam } \\
\text { fenolik }(\mathbf{m g} / \mathbf{L})\end{array}$ & $\begin{array}{l}\text { Toplam } \\
\text { flavonoid } \\
(\mathbf{m g} / \mathbf{L})\end{array}$ & $\begin{array}{l}\text { Toplam } \\
\text { karotenoid } \\
(\mathbf{m g} / \mathbf{L})\end{array}$ & $\begin{array}{l}\text { Antioksidan } \\
\text { aktivite }(\%)\end{array}$ & $\begin{array}{l}\text { Askorbik } \\
\text { asit }(\mathbf{m g} / \mathbf{L})\end{array}$ \\
\hline HPS & $960.5 \pm 67.5^{\mathrm{c}}$ & $7.67 \pm 0.14^{\mathrm{d}}$ & $19.07 \pm 1.86^{\mathrm{a}}$ & $85.18 \pm 0.20^{\mathrm{a}}$ & $29.23 \pm 3.56^{\mathrm{c}}$ \\
PPS & $897.6 \pm 31.0^{\mathrm{c}}$ & $9.58 \pm 0.05^{\mathrm{d}}$ & $18.57 \pm 2.71^{\mathrm{a}}$ & $84.76 \pm 0.67^{\mathrm{a}}$ & $26.28 \pm 1.06^{\mathrm{c}}$ \\
\%1 ÇPS & $2226.8 \pm 72.2^{\mathrm{b}}$ & $14.27 \pm 2.01^{\mathrm{c}}$ & $17.81 \pm 0.82^{\mathrm{a}}$ & $68.47 \pm 1.95^{\mathrm{c}}$ & $59.04 \pm 19.85^{\mathrm{b}}$ \\
\%2.5 ÇPS & $2127.1 \pm 65.5^{\mathrm{b}}$ & $17.64 \pm 1.81^{\mathrm{b}}$ & $10.61 \pm 2.09^{\mathrm{b}}$ & $77.72 \pm 0.91^{\mathrm{b}}$ & $48.46 \pm 0.58^{\mathrm{b}}$ \\
\%5 ÇPS & $2728.5 \pm 201.6^{\mathrm{a}}$ & $35.58 \pm 2.97^{\mathrm{a}}$ & $9.09 \pm 1.45^{\mathrm{b}}$ & $84.37 \pm 2.02^{\mathrm{a}}$ & $84.42 \pm 2.59^{\mathrm{a}}$ \\
\hline
\end{tabular}

Üretim aşamalarındaki (sütunlarda) farklı küçük harfler ile gösterilen örnekler arasındaki farklılıklar 0.05 düzeyinde önemlidir.

En yüksek karotenoid miktarı ham portakal suyunda $(19.07 \mathrm{mg} / \mathrm{L})$ iken en düşük karotenoid miktarı \% 5 çikolata ilave edilmiş pastörize portakal suyunda $(9.09 \mathrm{mg} / \mathrm{L})$ bulunmuştur. Pastörizasyon işleminin ve çikolata ilavesinin karotenoid miktarını düşürdüğü tespit edilmiştir (Tablo 4.) $\quad(\mathrm{p}<0.05)$. Gama ve Sylos (2007) pastörizasyon ve konsantrasyon işleminin Valensiya portakal suyunun karotenoidleri üzerine olan etkisini araştırmışlardır. Taze Valensiya portakal suyunun toplam karotenoid değerini $12.00 \pm 0.67 \mathrm{mg} / \mathrm{L}$ olarak tespit etmişken, $1 \mathrm{~s} 1 \mathrm{l}$ pastörizasyon ve konsantre edilen portakal suyunda bu değerleri sırası ile $10.40 \pm 6.90$ ve $9.90 \pm 5.30 \mathrm{mg} / \mathrm{L}$ olarak belirlemişlerdir.

Askorbik asit miktarları ham portakal suyunda $29.23 \mathrm{mg} / \mathrm{L}$, pastörize portakal suyunda 26.28 $\mathrm{mg} / \mathrm{L}, \% 1$ çikolata ilave edilmiş pastörize portakal suyunda $59,04 \mathrm{mg} / \mathrm{L}, \% 2.5$ çikolata eklenmiş pastörize portakal suyunda $48.6 \mathrm{mg} / \mathrm{L}$ ve $\% 5$ çikolata eklenmiş pastörize portakal suyunda 84.42 $\mathrm{mg} / \mathrm{L}$ olarak tespit edilmiştir (Tablo 4.). En yüksek askorbik asit değeri \%5 çikolata içeren pastörize portakal suyunda, en düşük askorbik asit değeri ise pastörize portakal suyunda bulunmuştur. Pastörizasyon işlemi askorbik asit değerini düşürürken çikolata ilavesi askorbik asit değerini arttırmıştır $(\mathbf{p}<0.05)$. Farnworth vd., (2001), Valensiya portakal sularını kullandıkları çalışmada pastörize edilmemiş ve $-18^{\circ} \mathrm{C}$ 'de dondurulmuş portakal sularının askorbik asit içeriğini 54.2 $\mathrm{mg} / 100 \mathrm{~mL}$, pastörize edilmiş ve $-18^{\circ} \mathrm{C}^{\prime} \mathrm{de}$ dondurulmuş portakal sularının askorbik asit içeriğini $53.7 \mathrm{mg} / 100 \mathrm{~mL}$ ve pastörize edilmiş ve $1^{\circ} \mathrm{C}$ 'de depolanmış portakal sularının askorbik asit içeriğini $49.6 \mathrm{mg} / 100 \mathrm{~mL}$ olarak tespit etmişlerdir. Askorbik asit konsantrasyonunun hem yöntemin farklılığından hem de depolama süresinden etkilendiğini bildirmişlerdir. Pastörize edilmiş ve 
$1^{\circ} \mathrm{C}$ 'de depolanmış portakal suyunun diğer portakal sularına kıyasla daha az askorbik asit içerdiği ve bütün portakal sularında depolama süresi arttıkça askorbik asidin önemli derecede azaldığı sonucuna varmışlardır.

Portakal suyunun antioksidan etkiye sahip olan askorbik asit, karotenoid ve fenolik bileşenleri önemli düzeyde yapısında bulundurmasından ötürü antioksidan aktivite değerinin yüksek çıkması beklenen bir durumdur (Ağçam, 2011). En yükssek antioksidan değeri ham portakal suyunda $\% 85.17$; en düşük değer ise $\% 1$ çikolata eklenmiş pastörize portakal suyunda \%68.47 olarak elde edilmiştir (Tablo 4.) $(\mathrm{p}<0.05)$. Çikolatalı portakal suyu örnekleri arasında antioksidan aktivitesi en yüksek örnek \%84.37 değeri ile $\% 5$ 'lik çikolata içeren portakal suyu olmuştur.

Bir çalışmada, 1sıl işleme tabi tutulmamış portakal sularında antioksidan aktivite \% 49.1 iken 1 s1l işlemle antioksidan aktivitenin \% 43.2 olduğu tespit edilmiştir (Scalzo vd., 2004). Gıdanın yapısı ve bileşimi, uygulanan 1 sıl işlemin türü ve sıcaklık derecesi fenolik bileşenlerin miktarında artışa neden olabilmektedir (Sakac vd., 2011).

\subsection{Portakal suyu örneklerinin renk değerleri \\ 3.5. Color values of orange juice samples}

Gıdaların rengi, tüketicinin satın alma davranışını etkileyen ve gıdanın kabul edilebilirliğinde dikkate değer etki yaratan temel kalite faktörlerinden biridir. Çünkü tüketici önce rengi algılamakta ve daha sonra renk yardımı ile lezzet ve aroma gibi diğer kalite kriterleri için bir ön fikir oluşturmaktadır. Renk, aynı zamanda taze gıdaların doğal olgunlaşma, depolama veya proses sırasındaki değişikliklerin bir göstergesidir (Ağçam, 2011). Portakal sularında tipik renk, genellikle karotenoidlerden ve bazı türlerde (kan portakal1) karotenoidler ile antosiyaninlerin karışımından kaynaklanmaktadır. Isıl işleme maruz kalma süresine göre rengin değiştiği bilinmektedir. Enzimatik olmayan esmerleşme reaksiyonlarının göstergesi olan L* değeri parlaklı̆̆ı ifade eder (Mahieddine vd., 2011). Basit bir ifade ile renk esmerleşmesi reaksiyonu sonucu L* (aydınlık) değeri azalmakta, a* (kırmızılık) değeri artmakta ve $b^{*}$ (sarılık) değeri ise azalmaktadır (Mertoğlu, 2015).

L*değeri en parlak olan ham portakal suyu (11.43) iken parlaklığı en düşük olan \%1 çikolata içeren pastörize portakal suyu olarak belirlenmiştir (18.12) ( $\mathrm{p}>0.05)$. $+\mathrm{a}^{*}$ en yüksek (kırmızılık) \%5 çikolata eklenmiş pastörize portakal suyunda (16.63) bulunurken $-a^{*}$ değeri en fazla (yeşillik) pastörize portakal suyunda (0.38) olarak tespit edilmiştir $(p<0.05)$. $+b^{*}($ sarılık) değeri en fazla $\% 1$ çikolata içeren pastörize portakal suyunda (30.85) iken - $\mathrm{b}^{*}$ değeri (mavilik) değeri ham portakal suyunda(19.55) bulunmuştur $(\mathrm{p}>0.05)$. Hue değeri en yüksek pastörize portakal suyunda (88.99) iken en düşük \%5 çikolata içeren pastörize portakal suyunda (59.64) olarak bulunmuştur $(\mathrm{p}<0.05)$. Kroma değeri en yüksek \% 2.5 çikolata içeren pastörize portakal suyunda (33.14) çıkarken en düşük değer ise ham portakal suyunda (19.57) olarak tespit edilmiştir (Tablo 5.). ( $\mathrm{p}>0.05)$.

Iş1k (2008), portakal suyu renginin kırmızılığını ifade eden a* değerlerinde sıcaklık artışı ile birlikte pozitif yönde değişim gerçekleştiğini bildirmiştir. Lee vd., (2003), pastörize portakal sularında L* değerinde 40.22 \pm 0.16 ' dan 41.22 \pm 0.81 'e küçük bir artış olduğunu bildirmişlerdir. Isıl işlemden sonra, $\mathrm{b}^{*}$ değerlerinin $(17.62 \pm 0.35)$ bütün örneklerde yavaş yavaş pozitif yönde, $\mathrm{a}^{*}$ değerlerinin $1.75 \pm 0.07$ ' den $-2.64 \pm 0.15(\mathrm{p}<0.05)$ ' ye bir parça negatif yönde değiştiğini belirlemişlerdir. Lee vd., (2003), taze portakal suyu örneğinde Hue değerini $95.66^{\circ}$ ve 1 s1l pastörizasyon maruz kalan örnekte ise $97.51^{\circ}$ tespit etmiştir.

Tablo 5. Portakal suyu örneklerinin renk değerleri

Table 5. Color values of orange juice samples

\begin{tabular}{ccccccc}
\hline Örnekler & $\mathbf{L}^{*}$ & $\mathbf{a}^{*}$ & $\mathbf{b}^{*}$ & Hue & Kroma & $\begin{array}{c}\text { Esmerleşme } \\
\text { İndeksi(abs.) }\end{array}$ \\
\hline HPS & $11.43 \pm 0.14^{\mathrm{a}}$ & $0.91 \pm 0.08^{\mathrm{c}}$ & $19.55 \pm 0.23^{\mathrm{a}}$ & $87.34 \pm 0.20^{\mathrm{a}}$ & $19.57 \pm 0.23^{\mathrm{b}}$ & $0.270 \pm 0.044^{\mathrm{b}}$ \\
PPS & $17.89 \pm 5.61^{\mathrm{a}}$ & $0.38 \pm 0.46^{\mathrm{c}}$ & $30.38 \pm 9.40^{\mathrm{a}}$ & $88.99 \pm 1.43^{\mathrm{a}}$ & $30.39 \pm 9.39^{\mathrm{ab}}$ & $0.236 \pm 0.035^{\mathrm{b}}$ \\
$\% 1$ ÇPS & $18.12 \pm 5.87^{\mathrm{a}}$ & $7.53 \pm 5.74^{\mathrm{b}}$ & $30.85 \pm 9.89^{\mathrm{a}}$ & $78.07 \pm 8.09^{\mathrm{b}}$ & $31.91 \pm 10.77^{\mathrm{a}}$ & $0.583 \pm 0.048^{\mathrm{a}}$ \\
$\% 2.5$ ÇPS & $17.79 \pm 0.75^{\mathrm{a}}$ & $13.19 \pm 0.40^{\mathrm{a}}$ & $30.40 \pm 1.24^{\mathrm{a}}$ & $66.51 \pm 1.48^{\mathrm{c}}$ & $33.14 \pm 0.98^{\mathrm{a}}$ & $0.636 \pm 0.116^{\mathrm{a}}$ \\
$\% 5$ ÇPS & $16.60 \pm 0.15^{\mathrm{a}}$ & $16.63 \pm 0.18^{\mathrm{a}}$ & $28.38 \pm 0.19^{\mathrm{a}}$ & $59.64 \pm 0.45^{\mathrm{d}}$ & $32.89 \pm 0.07^{\mathrm{a}}$ & $0.617 \pm 0.037^{\mathrm{a}}$ \\
\hline Üretim aşamalarnndaki (sütunlarda) farkl küçük harfler ile gösterilen örnekler arasndaki farkll1kklar 0.05 düzeyinde önemlidir.
\end{tabular}

En yüksek esmerleşme indeksi değeri \%2.5 çikolata içeren pastörize portakal suyunda 0.636 (abs.); en düşük değer ise pastörize portakal suyunda 0.236 (abs.) olarak bulunmuştur (Tablo 5.) $(\mathrm{p}<0.05)$. 


\subsection{Portakal suyu örneklerinin duyusal analiz değerleri}

3.6. Sensory analysis values of orange juice samples

Portakal suyu örneklerine ait duyusal analiz sonuçları Tablo 6' da gösterildiği gibidir.

Tablo 6. Portakal suyu örneklerinin duyusal değerleri

Table 6. Sensory values of orange juice samples

\begin{tabular}{cccccc}
\hline Örnekler & Renk & Bulanıklık & Tat ve Lezzet & Koku & Genel İzlenim \\
& & & & & \\
\hline HPS & $4.15 \pm 0.90^{\mathrm{a}}$ & $4.15 \pm 0.69^{\mathrm{a}}$ & $3.92 \pm 0.95^{\mathrm{a}}$ & $4.23 \pm 0.83^{\mathrm{a}}$ & $4.15 \pm 0.69^{\mathrm{a}}$ \\
PPS & $4,00 \pm 1.04^{\mathrm{a}}$ & $4.30 \pm 0.89^{\mathrm{a}}$ & $3.80 \pm 1.03^{\mathrm{a}}$ & $3.80 \pm 1.05^{\mathrm{a}}$ & $3.90 \pm 0.84^{\mathrm{a}}$ \\
$\% 1$ ÇPS & $3.31 \pm 1.11^{\mathrm{a}}$ & $3.35 \pm 1.25^{\mathrm{a}}$ & $3.46 \pm 1.05^{\mathrm{a}}$ & $3.46 \pm 1.39^{\mathrm{a}}$ & $3.54 \pm 0.88^{\mathrm{a}}$ \\
$\% 2.5$ ÇPS & $3.38 \pm 1.19^{\mathrm{a}}$ & $3.08 \pm 1.12^{\mathrm{a}}$ & $3.46 \pm 1.13^{\mathrm{a}}$ & $3.38 \pm 1.45^{\mathrm{a}}$ & $3.54 \pm 1.13^{\mathrm{a}}$ \\
\% ÇPS & $3.31 \pm 1.09^{\mathrm{a}}$ & $3.31 \pm 1.32^{\mathrm{a}}$ & $3.58 \pm 1.35^{\mathrm{a}}$ & $3.62 \pm 1.39^{\mathrm{a}}$ & $3.58 \pm 1.15^{\mathrm{a}}$ \\
\hline Üretim asamalarndaki (sütunlarda) farklı küç̈k harfler ile gösterilen örnekler arasndaki farklılıklar 0.05 düzeyinde önemlidir.
\end{tabular}

Üretim aşamalarındaki (sütunlarda) farklı küçük harfler ile gösterilen örnekler arasındaki farklılıklar 0.05 düzeyinde önemlidir.

Yapılan çalışmada renk olarak en çok beğenilen örnek ham portakal suyu (4.15) olmuştur ( $\mathrm{p}>0.05)$. Çikolata eklenen pastörize portakal sularında renk olarak en çok \%2.5'lik ÇPS (3.38) beğenilmiştir. Bulanıklık portakal suyunda istenilen bir özelliktir. Bulanıklık özelliği en çok beğeni alan pastörize portakal suyu (4.15) iken, en az beğeni alan portakal suyu örneği ise \%2.5'lik ÇPS (3.08) örneği olmuştur $(\mathrm{p}>0.05)$. Tat ve lezzet değerleri bakımından en çok beğenilen HPS örneği 3.92 puan almıştır. Çikolata ilavesi içeren portakal sularında ise en çok \%5'lik ÇPS örneğinin beğenildiği (3.58) sonucuna varılmıştır ( $p>0.05)$. Koku değerleri bakımından en çok ham portakal suyu örneğinin beğenildiği (4.23) tespit edilmiştir. Çikolata ilavesi içeren portakal suları arasında ise en çok \%5'lik ÇPS'nin beğenildiği (3.62) sonucuna varılmıştır $(\mathrm{p}>0.05)$. Genel izlenim olarak baktığımızda en çok ham portakal suyunun beğenilmiş olduğu (4.15) tespit edilmiştir. Çikolata ilave edilen portakal suları arasında en çok $\% 5$ çikolata eklenmiş pastörize portakal suyu (3.58) beğenilmiştir. \%1'lik ve \%2.5'luk ÇPS'lerde aynı oranda beğenildiği sonucuna varılmıştır $(\mathrm{p}>0.05)$.

\section{Sonuçlar \\ 4. Results}

$\mathrm{Bu}$ çalışmada, meyve olarak $\mathrm{C}$ vitamini, fenolik madde ve antioksidan aktivite yönünden zengin içeriğe sahip olan portakal ile mutluluk hormonu salgılayan ve insanlar tarafindan çokça tercih edilen çikolata bir araya getirilerek, faydalı iki üründen yeni bir ürün elde edilmiştir. Literatürde bu yeni ürün ile ilgili herhangi bir çalışma bulunmamıştır. Bu ilk verilerin yeni çalışmaların yapılmasını teşvik edeceği düşünülmektedir. En yüksek fenolik madde miktarı $(2728.5 \mathrm{mg} / \mathrm{L})$, flavonoid madde miktarı $(35.58 \mathrm{mg} / \mathrm{L})$ ve askorbik asit değerleri de $(84.42 \mathrm{~g} / \mathrm{mL})$ yine $\% 5$ çikolata içeren pastörize portakal suyunda ölçülmüştür. Çikolatalı portakal suyu örnekleri arasında antioksidan aktivitesi en yüksek örnek $\% 84.37$ değeri ile $\% 5$ oranında çikolata içeren portakal suyu olmuştur. Çikolata ilave edilen portakal suları arasındaki duyusal analiz bakımından en çok $\% 5$ çikolata eklenmiş pastörize portakal suyu (3.58) beğenilmiştir. $\mathrm{Bu}$ iki bileşimden ürettiğimiz çikolatalı portakal suyunun hem lezzet açısından hem de yüksek antioksidan içeriğinden dolayı sağlığa yararı açısından faydalı olacağ 1 düşünüldüğü için bu ürünün günlük diyetlerde alınması tavsiye edilmektedir. Ayrıca çikolatalı portakal suyunun meyve suyu sanayiinde üretiminin yapılması hem tüketici hem de üretici açısından yarar sağlayacaktır.

\section{Teşekkür \\ Acknowledgement}

$\mathrm{Bu}$ çalışmada emeği geçen değerli arkadaşımız Aliye ERDEM'i sayg1 ve rahmetle aniyoruz. Ayrıca bu çalışmanın gerçekleştirilmesinde laboratuvar olanaklarından faydalandığımız Kilis 7 Aralık Üniversitesi'ne teşekkür ederiz. Ayrıca makalenin inceleme ve değerlendirme aşamasında yapmış olduklanı katkılardan dolayı editör ve hakem/hakemlere teşekkür ederiz.

\section{Yazar katkısı \\ Author contribution}

Birinci yazar makalenin konusunun seçiminde, konunun şekillenmesinde, yapılacak analizlerin neler olması gerektiğine karar vererek makaleyi kurgulamış, hesaplamalar ve istatistiksel analizleri yürütmüştür. Diğer yazarlar ise laboratuvarda yapılan analizler ile makale yazımına eşit oranda katkı sağlamışlardır. 


\section{Etik beyanı}

Declaration of ethical code

$\mathrm{Bu}$ çalışmada, "Yükseköğretim Kurumları Bilimsel Araştırma ve Yayın Etiği Yönergesi”" kapsamında uyulması gerekli tüm kurallara uyulduğunu, bahsi geçen yönergenin "Bilimsel Araştırma ve Yayın Etiğine Aykırı Eylemler" başlığı altında belirtilen eylemlerden hiçbirinin gerçekleştirilmediğini taahhüt ederiz.

\section{Çıkar çatışması beyanı \\ Conflicts of interest}

Yazarlar herhangi bir çıkar çatışması olmadığını beyan eder.

\section{Kaynaklar}

References

Ağçam, E. (2011). Vurgulu elektrik alan ve isll işlem uygulamalarının portakal suyunun özellikleri ve raf ömrü üzerine etkisi [Yüksek Lisans Tezi, Ç.Ü. Fen Bilimleri Enstitüsü].

Anonim, (1990). Çikolata TS 7800. Türk Standartları Enstitüsü, Ankara.

Anonim, (2010). Her derde deva, sağliklı lezzet: Çikolata. (2018, $26 \quad$ Kasım) http://www.nestle.com.tr /Beslenme.aspx?id=1

Akgün, C. (2006). Turunçgil Sektör Profili. Dış Ticaret Şubesi Uygulama Servisi. Ankara.

Altuğ, T. (1993). Duyusal Test Teknikleri. Ege Üniversitesi Mühendislik Fakültesi Ders Kitapları Yayın No: 28.

Bek, Y., \& Efe, E. (1988). Araştırma ve Deneme Metotları-I. Ç.Ü. Ziraat Fakültesi Ders Kitabı. No: 71, Ç.Ü. Ziraat Fakültesi Ofset ve Teksir Atölyesi.

Burdurlu, H.S., Koca, N., \& Karadeniz, F. (2006). Degradation of vitamin $\mathrm{c}$ in citrus juice concentrates during storage. Journal of Food Engineering, 74, 211-216. https://doi.org/10.1016/j.jfoodeng.2005.03.026.

Cemeroğlu, B. (2004) Meyve ve Sebze İşleme Teknolojisi 1.Cilt. Kültür ve Turizm Bakanlığı Yayınları.

Cemeroğlu, B. (1992). Meyve ve sebze işleme endüstrisinde temel analiz metodları. Biltav Yayıncilı.

Cemeroğlu, B. (2007). Gida Analizleri. Gıda Teknolojisi Derneği Yayınları, No:34.
Chun, O.K., Kim, D., Smith, N., Schroeder, D., Han, J.T., \& Lee, C.Y. (2005). Daily consumption of phenolics and total antioxidant capacity from fruit and vegetables in the American diet. Journal of Agricultral Food Chemistry, 85, 1715-1724. https://doi.org/10.1002/jsfa.2176.

Coe, S.D., \& Coe, M. (1996). The true history of chocolate. Thames\&Hudson.

Dhuique-Mayer, C., Caris-Veyrat, C., Tbatou, M., Amiot, M.J., Carail, M., \& Dornier, M. (2007). Thermal degradation of antioxidant micronutrients in citrus juice: kinetics and newly formed compounds. Journal of Agricultural Food Chemistry, 55, 4209-4216. https://doi.org/10.1021/jf0700529.

Esteve, M.J., Frigola, A., Rodrigo, C. \& Rodrigo, D. (2005). Effect of storage period under variable conditions on the chemical and physical composition and colour of spanish refrigerated orange juices. Food and Chemical Toxicology, 43 , 1413-142. https://doi.org/10.1016/j.fct.2005.03.016.

Farnworth, E.R., Lagaceaà, M., Couture, R., Yaylayan V., \& Stewart, B. (2001). Thermal processing, storage conditions, and the composition and physical properties of orange juice. Food Research International, 34, 25-30. https://doi.org/10.1016/S0963-9969(00)001241.

Gama, J. J. T., \& Sylos, C. M. (2007). Effect of thermal pasteurization and concentration on carotenoid composition of brazilian valencia orange juice. Food Chemistry, 100, 1686-1690. https://doi.org/10.1016/j.foodchem.2005.01.062.

Hasdemir, M. (2007). Turunçgiller. Tarımsal Ekonomi Araştırma Enstitüsü. T.E.A.E.-Bakış, Sayı: 9, Nüsha.

Işık, Ö. (2008). Pastörizasyon sıcaklığının kozan yerlisi ve hamlin portakallarindan üretilen meyve sularının kalitesi üzerine etkisi [Yüksek lisans Tezi, Ç.Ü. Fen Bilimleri Enstitüsü].

Kargın, D. ve Güneş, F.E. (2017). Çikolatanın kardiyovasküler sistem üzerine etkileri. Gümüshane Üniversitesi Sağllk Bilimleri Dergisi, 6(4):234-246.

Kimball, D. A. (1991). Citrus processing quality control and technology. An AVI Book, Published by Von Nostrand Reinhold Newyork.

Klimczak, I., Malecka, M., Szlachta, M., \& Gliszczyńska-Świglo, A. (2007). Effect of storage on the content of polyphenols, vitamin $\mathrm{c}$ and the antioxidant activity of orange juices. Journal of Food Composition and Analysis, 20, 
313-322.

https://doi.org/10.1016/j.jfca.2006.02.012.

Lee, H. S., \& Castle, W. S. (2001). Seasonal changes of carotenoid pigments and color in hamlin, earlygold, and budd blood orange juices. Journal of Agricultural Food Chemisty, 49, 877-88. https://doi.org/10.1021/jf000654r.

Lee, H. S., \& Kim, J. G. (2003). Effects of debittering on red grapefruit juice concentrate. Food Chemistry, 82, 177-180. https://doi.org/10.1016/S0308-8146(02)002807.

Li-Ying, N., Ji-Hong, W., Xiao-Jun, L., Fang, C., Zheng-Fu, W., Guanghua, Z., \& Xiasong, H. (2008). Physicochemical characteristics of orange juice samples from seven cultivars. Agricultural Sciences in China, 7(1), 41-47. https://doi.org/10.1016/S1671-2927(08)600206.

Mahieddine, B., Faouzi, S. M., Hedjer, S., Moussa, H., Aissa, B., \& Mahmoud, S. (2011). Heat treatment effect on the technological quality of processed tomato paste. Canadian Journal on Chemical Engineering and Technology, 2(3), 27-40.

Meydav, S., Saguy, I., \& Kopelman, J. I. (1977). Browning determination in citrus products. Journal of Agricultural and Food Chemistry, 25(3), 602-604. https://doi.org/10.1021/jf60211a030.

Mertoğlu, T. Ş. (2015). Portakal suyunun bileşimi ve hmf oluşum kinetiği üzerine isıl işlem ve depolamanın etkileri [Yüksek Lisans Tezi Ç.Ü. Fen Bilimleri Enstitüsü].

Parish, M. E. (1998). Orange juice quality after treatment by thermal pasteurization or isostatic high pressure. Lebensmittel-Wissenschaft undTechnologie, $\quad 31, \quad 439-\quad 442$. https://doi.org/10.1016/s0023-6438(02)00087-7.

Polydera, A. C., Stoforos, N. G., \& Taoukis, P. S. (2004). The effect of storage on the antioxidant activity of reconstituted orange juice which had been pasteurized by high pressure or heat. International Journal of Food Science and Technology, 39, 783-791. https://doi.org/10.1111/j.13652621.2004.00844.x.

Polydera, A. C., Stoforos, N. G., \& Taoukis, P. S. (2005). Quality degradation kinetics of pasteurised and high pressure processed fresh navel orange juice. Nutritional Parameters and Shelf Life. Innotive Food Science and Emerging Technologies, $6, \quad 1-9$. https://doi.org/10.1016/j.ifset.2004.10.004.

Sànchez-Moreno, C., Plaza, L., De Ancos, B., \& Cano, M. P. (2003). Quantitative bioactive compounds assessment and their relative contribution to the antioxidant capacity of commercial orange juices, Journal of Agricultural and Food Chemistry, 83, 430-439. https://doi.org/10.1002/jsfa.1392.

Sakac, M., Torbica, A., Sedej, I., \& Hadnadev, M. (2011). Influence of breadmaking on antioxidant capacity of gluten free breads based on rice and buckwheat flours. Food Research International, $44,2806-2813$. https://doi.org/10.1016/j.foodres.2011.06.026.

Scalzo, R. L., Iannoccari, T., Summa, C., Morelli, R., \& Rapisarda, P. (2004). Effect of thermal treatments on antioxidant and antiradical activity of blood orange juice. Food Chemistry, 85, 4147.

https://doi.org/10.1016/j.foodchem.2003.05.005.

Selli, S., Cabaroğlu, T., \& Canbaş, A. (2004). Volatile flavour compenents of orange juice obtained from the cv. Kozan of Turkey. Journal of Food Composition and Analysis, 17, 789-796. https://doi.org/10.1016/j.jfca.2003.10.005.

Thamke, I., Dürrschmid K., \& Rohm, H. (2009). Sensory description of dark chocolates by consumers. LWT - Food Science and Technology, 42, 534-539. https://doiorg/10.1016/j.lwt.2008.07.006.

Uçan Türkmen, F., \& Mercimek Takci, H.A. (2018). Ultraviolet-c and ultraviolet-b lights effect on black carrot (Daucus carota ssp. sativus) juice. Journal of Food Measurement and Characterization, 12(2), 1038-1046. https://doi.org/10.1007/s11694-018-9719-2.

Xu, G., Ye, X., Chen, J., \& Liu, D. (2007). Effect of heat treatment on the phenolic compounds and antioxidant capacity of citrus peel extract. Journal of Agricultural and Food Chemistry, 55, 330-335. https://doi.org/10.1021/jf0625171.

Watts, B. M., Ylimaki, G. L., Jeffery, L. E., \& Elias, L. G. (1989). Basic sensory methods for food evaluation. The International Development Research Centre. 